\title{
Penerapan Metode Topsis dalam Pemilihan Leader official PKKMB Terbaik
}

\author{
Wanda Rizki Fadillah1', Fauziah ${ }^{2}$, Asri Yustika ${ }^{3}$, Lola Alfiza ${ }^{4}$, Eka Irawan ${ }^{5}$ \\ STIKOM Tunas Bangsa Pematangsiantar \\ Jl. Jend. Sudirman Blok A No.1/2/3 Pematangsiantar, Medan, Indonesia, 21127 \\ Email : wandarizkifadillah19@gmail.com², Fauziahsyahrul15@gmail.com² \\ asriyustika04@gmail.com ${ }^{3}$, Lolaafiza05@gamail.com ${ }^{4}$, eka.irawan@amiktunasbangsa.ac.id ${ }^{5}$
}

\begin{abstract}
Introduction of New Student Campus Life (INSCL) is an introduction to study programs and educational programs, scientific culture and fostering student activities in universities for new students. This research is motivated by the problem of selecting students who will become Official Leaders often do not meet the criteria needed by student affairs and hinder the performance of student affairs. To overcome this problem a Decision Support System (SPK) is needed which is expected to solve problems in selecting the best Official Leader with the TOPSIS method with assessment criteria, namely GPA, Semester, Organizational Experience, Discipline, Integrity (Seriousness). The results of the application of the TOPSIS method in this study were the selection of the eight highest ranking alternatives, namely A10, A9, A8, A2, A3, A6, A7, A1 to become Official Leaders on PKKMB in $A M I K$ and STIKOM Tunas Bangsa Pematangsiantar.
\end{abstract}

Keywords: Decision Support System (DSS), Leader Official, INSCL, TOPSIS.

Abstrak- Perkenalan Kehidupan Kampus Mahasiswa Baru (PKKMB) adalah kegiatan pengenalan terhadap program studi dan program pendidikan, budaya ilmiah dan pembinaan kegiatan kemahasiswaan di perguruan tinggi bagi mahasiswa baru. Penelitian ini dilatar belakangi oleh permasalahan pemilihan mahasiswa yang akan menjadi Leader Official sering tidak memenuhi kriteria yang di butuhkan oleh pihak kemahasiswaan dan menghambat kinerja pihak kemahasiswaan. Untuk mengatasi permasalahan tersebut diperlukan Sistem Pendukung Keputusan (SPK) yang diharapkan menyelesaikan permasalahan dalam pemilihan mahasiswa sebagai Leader Official terbaik dengan metode TOPSIS dengan kriteria penilaian yaitu IPK, Semester, Pengalaman Organisasi, Kedisiplinan, Integritas(Kesungguhan). Hasil dari penerapan metode TOPSIS pada penelitian ini adalah terpilihnya 8 alternatif dengan peringkat yang paling tinggi yaitu $A 10, A 9, A 8, A 2, A 3$, A6, A7, A1 untuk menjadi Leader Official pada PKKMB di AMIK dan STIKOM Tunas Bangsa Pematangsiantar.

Kata kunci: Sistem Pendukung Keputusan (SPK), Leader Official, PKKMB, TOPSIS.

\section{PENDAHULUAN}

Leader Official atau yang sering di sebut juga sebagai senior pendamping adalah mahasiswa yang mempunyai tupoksi sebagai pendamping sekaligus pengarah bagi calon mahasiswa baru yang berkaitan dalam proses pengenalan kehidupan kampus. Perkenalan Kehidupan Kampus Mahasiswa Baru (PKKMB) adalah kegiatan pengenalan terhadap program studi dan program pendidikan, budaya ilmiah dan pembinaan kegiatan kemahasiswaan di perguruan tinggi bagi mahasiswa baru. Pengenalan kampus yang lebih rinci dinilai perlu untuk mengingatkan kembali tentang penyelenggaraan proses belajar mengajar berbasis kompetensi yang memerlukan syarat pemahaman tentang learning to know, 
learning to do, learning to live togeher, dan learning to be dari program studi yang akan ditempuh secara benar dan sedini mungkin, kemampuan beradaptasi dengan lingkungan belajar secara cepat agar proses pembelajaran berlangsung dalam suasana atmosfir yang baik, dan sistem pembelajaran mahasiswa yang tepat untuk percepatan proses pemahaman makna programstudi yang dimasuki \& adaptasi dengan lingkungan kampus[1].

Penilitian ini dilakukan di kampus AMIK dan STIKOM Tunas Bangsa Pematangsiantar. Hasil penilaian harus dievaluasi berdasarkan kriteria-kriteria yang sudah ditentukan oleh pihak kemahasiswaan dalam memilih mahasiswa sebagai leader official (pembimbing) dalam Perkenalan Kehidupan Kampus Mahasiswa Baru (PKKMB). Bagian kemahasiswaan harus cermat dalam memberikan analisa penilaian dari panitia pmb(penerimaan mahasiswa baru) agar tidak terjadi kesalahan dalam penilaian hasil wawancara. Penelitian terdahulu yang berkaitan dengan metode TOPSIS adalah tentang Sistem Pendukung Keputusan Penentuan Karyawan Kontrak Menjadi Karyawan Tetap Menggunakan Metode Topsis [2], Sistem Pendukung Keputusan untuk Rekomendasi Kelulusan Sidang Skripsi Menggunakan Metode AHP-TOPSIS [3], dan Sistem Pendukung Keputusan Pemberian Beasiswa Kepada Peserta Didik Baru Menggunakan Metode TOPSIS[4].

\section{METODOLOGI PENELITIAN}

\subsection{Sistem Pendukung Keputusan(SPK)}

Sistem Pendukung Keputusan (SPK) adalah salah satu cara mengorganisir informasi yang dimaksudkan untuk digunakandalam membuat keputusan [5]. Sistem Pendukung Keputusan adalah sistem penghasil informasi spesifik yang ditujukan untuk memecahkan suatu masalah tertentu yang harus dipecahkan oleh manager pada berbagai tingkatan [6]-[16]. Dengan kata lain Sistem Pendukung Keputusan adalah suatu sistem informasi berbasis komputer yang menghasilkan berbagai alternatif keputusan untuk membantu manajemen dalam menangani berbagai permasalahan yang terstruktur dengan menggunakan data dan model[17].

\subsection{Technique for Order Performance of Similarity to Ideal Solution (TOPSIS)}

Technique for Order Performance of Similarity to Ideal Solution (TOPSIS) merupakan salah satu sistem pendukung keputusan multikriteria. TOPSIS mempunyai prinsip bahwa alternatif yang terpilih harus mempunyai jarak terdekat dari solusi ideal positif dan mempunyai jarak terjauh dari solusi ideal negatif dari sudut pandang geometris dengan menggunkana jarak Euclidean (jarak antara dua titik) untuk menentukan kedekatan relatif dari suatu alternatif.

Metode TOPSIS memiliki keuntungan sebagai berikut:

a. Metode Topsis merupakan salah satu metode yang simple dan konsep rasional yang mudah dipahami.

b. Metode Topsis mampu untuk mengukur kinerja relatif dalam membentuk form matematika sederhana.[18]

Tahapan metode Topsis:

a. Membuat matriks keputusan yang ternormalisasi. 
b. Membuat matriks keputusan yang ternormalisasi terbobot.

c. Menentukan matriks solusi ideal positif dan matriks solusi ideal negatif.

d. Menentukan jarak antara nilai setiap alternatif dengan matriks solusi ideal positif dan negatif.

e. Menentukan nilai preferensi untuk setiap alternatif[18]

TOPSIS membutuhkan rating kinerja setiap alternatif $A i$ pada setiap kriteria Ci yang ternormalisasi, yaitu:

Adapun rumus - rumus yang digunakan pada metode Topsis adalah:

a. Menetukan normalisasi matriks keputusan. Nilai ternormalisasi Rij dihitung dengan rumus:

$$
\mathrm{R}_{\mathrm{ij}}=\frac{X i j}{\sqrt{\sum_{i=1}^{m} X_{i j}^{2}}} ;
$$

Keterangan :

$\mathrm{i}=1,2, \ldots, \mathrm{m}$

$\mathrm{j}=1,2, \ldots, \mathrm{n}$

b. Menetukan bobot ternormalisasi matriks keputusan. Nilai bobot ternormalisasi yij sebagai berikut:

$$
\mathrm{y}_{\mathrm{ij}}=\mathrm{w}_{\mathrm{ij}} \mathrm{r}_{\mathrm{ij}} \text {; }
$$

Keterangan :

$\mathrm{i}=1,2, \ldots, \mathrm{m}$

$\mathrm{j}=1,2, \ldots, \mathrm{n}$

Dengan :

$$
\begin{aligned}
& \mathrm{A}^{+}=\left(y_{1}^{+}, y_{2}^{+}, \ldots, y_{n}^{+}\right) ; \\
& \mathrm{A}^{-}=\left(y_{1}^{-}, y_{2}^{-}, \ldots, y_{n}^{-}\right) ;
\end{aligned}
$$

$y_{1}^{+}=\left\{\begin{array}{c}\max y i j ; j i k a j \text { adalah atribut keuntungan } \\ \max y i j ; j i k a j \text { adalah atribut biaya }\end{array}\right.$

$y_{1}^{-}=\left\{\begin{array}{c}\max y i j ; j i k a j \text { adalah atribut keuntungan } i \\ \max y i j ; j i k a j \text { adalah atribut biaya } i\end{array}\right.$

Dengan nilai $\mathrm{j}=1,2, \ldots, \mathrm{n}$

1) Jarak antara alternatif $A_{i}$ dengan solusi ideal positif dirumuskan sebagai :

$$
D_{i}^{+}=\sqrt{\sum_{j=1}^{n}\left(y_{1}^{+}-y i j\right)^{2}} ;
$$

Keterangan :

$$
\mathrm{I}=1,2, \ldots, \mathrm{m}
$$

2) Jarak antara alternatif $A_{i}$ dengan solusi ideal positif dirumuskan sebagai :

$$
D_{i}^{-}=\sqrt{\sum_{j=1}^{n}\left(y_{1}^{+}-y_{i}^{-}\right)^{2}}
$$

Keterangan :

Dengan $\mathrm{i}=1,2, \ldots, \mathrm{m}$

3) Nilai prefensi untuk setiap alternatif $\left(\mathrm{V}_{\mathrm{i}}\right)$ diberikan sebagai: 


$$
\mathrm{V}_{\mathrm{i}}=\frac{D_{i}^{-}}{D_{i}^{-}+D_{i}^{+}} ; \quad \mathrm{i}=1,2, \ldots, \mathrm{m}
$$

Nilai $V_{i}$ yang lebih besar menunjukkan bahwa alternatif $A_{i}$ lebih di pilih.

\section{HASIL DAN PEMBAHASAN,}

\subsection{Proses Data Masukan}

Data yang di peroleh dari hasil wawancara selanjutnya diolah menjadi data olahan, dapat di lihat pada tabel 1.

Tabel 1. Data Olahan Wawancara

\begin{tabular}{|c|c|c|c|c|c|c|}
\hline \multirow[b]{2}{*}{ No } & \multirow[b]{2}{*}{ Alternatif } & \multicolumn{5}{|c|}{ Kriteria } \\
\hline & & Ipk & Semester & $\begin{array}{c}\text { Pengalaman } \\
\text { Organisasi }\end{array}$ & Kedisiplinan & $\begin{array}{c}\text { Integritas } \\
\text { (Kesungguhan) }\end{array}$ \\
\hline 1 & Retno Rafika & 3,57 & 4 & 1 tahun & Baik & Cukup \\
\hline 2 & Hanifa Urbach Sari & 3,62 & 4 & 2 tahun & Sangat Baik & Baik \\
\hline 3 & Ella Tri Nadya & 3,67 & 4 & 1 tahun & Baik & Baik \\
\hline 4 & Imam Ghofarli Harahap & 2,91 & 2 & 3 tahun & Baik & Cukup \\
\hline 5 & Mhd. Iqbal Al Farizi & 3,11 & 2 & 1 tahun & Cukup & Baik \\
\hline 6 & Huda Fadiya Daulay & 3,65 & 2 & 3 tahun & Baik & Cukup \\
\hline 7 & Azhar Fadilah Zuhri & 3,45 & 2 & 2 tahun & Baik & Cukup \\
\hline 8 & Awaluddin Kurniawan & 3,89 & 2 & 3 tahun & Cukup & Baik \\
\hline 9 & $\begin{array}{l}\text { Elrlangga Amara Putra } \\
\text { Samodra }\end{array}$ & 3,53 & 6 & 3 tahun & Sangat Baik & Sangat Baik \\
\hline 10 & Eka Satria Pribadi & 3,73 & 6 & 2 tahun & Baik & Sangat Baik \\
\hline
\end{tabular}

Dalam perhitungan TOPSIS Ditentukan kriteria - kriteria yang akan menjadi acuan dalam pengambilan keputusan dan pemberian bobot penilaian untuk setiap kriteria. Berdasarkan data yang diperoleh dari hasil wawancara didapatkan input kriteria, bobot, subskriteria dan nilai skor dapat di lihat pada tabel 2.

Tabel 2. Tabel Kriteria Penilaian dan Bobot

\begin{tabular}{|l|l|l|l|l|}
\hline Kriteria & Keterangan & Bobot & Subskriteria & Nilai \\
\hline K1 & IPK & $30 \%$ & $<2.8$ & 25 \\
\hline & & & $2.9-3.2$ & 50 \\
\hline & & & $3.3-3.6$ & 75 \\
\hline K2 & Semester & $10 \%$ & $2.7-4$ & 100 \\
\hline & & & 4 & 50 \\
\hline & & & 6 & 75 \\
\hline K3 & Pengalaman & $15 \%$ & Tidak Pernah & 25 \\
& Organisasi & & & 100 \\
\hline & & & 1 Tahun & 50 \\
\hline & & & $1-2$ Tahun & 75 \\
\hline K4 & & & $>2$ Tahun & 100 \\
\hline & Kedisiplinan & $20 \%$ & Cukup & 50 \\
\hline & & & Baik & 75 \\
\hline K5 & Integritas & $25 \%$ & Cukup & 50 \\
\hline & & & Baik & 75 \\
\hline & & & Sangat Baik & 100 \\
\hline
\end{tabular}


Dalam penelitian ini akan di pilih 8 dari 10 orang mahasiswa untuk menjadi leader official pada PKKMB AMIK dan STIKOM Tunas Bangsa Pematangsiantar adalah sebagai berikut:

A1= Retno Rafika; A2= Hanifa Urbach Sari; A3 = Ella Tri Nadya; A4 = Imam Ghofarli Harahap; A5 = Mhd. Iqbal Al Farizi; A6 = Huda Fadiya Daulay; A7 = Azhar Fadilah Zuhri; A8 = Awaluddin Kurniawan; A9 = Elrlangga Amara Putra Samodra; A10 = Eka Satria Pribadi;

Menentukan rating kecocokan dari setiap alternatif pada setiap kriteria terlihat pada tabel 3.

Tabel 3. Rating Kecocokan

\begin{tabular}{|l|l|}
\hline Nilai & Keterangan \\
\hline 25 & Sangat Kurang \\
\hline 50 & Kurang \\
\hline 75 & Baik \\
\hline 100 & Sangat Baik \\
\hline
\end{tabular}

Dilakukan normalisasi pada data olahan wawancara untuk mengetahui kecocokan alternatif terhadap kriteria dapat di lihat pada tabel 4.

Tabel 4. Kecocokan Alternatif Terhadap Kriteria

\begin{tabular}{|c|c|c|c|c|c|c|}
\hline \multirow{2}{*}{ No } & Alternatif & \multicolumn{5}{|c|}{ Kriteria } \\
\cline { 3 - 7 } & & Ipk & Semester & $\begin{array}{c}\text { Pengalaman } \\
\text { Organisasi }\end{array}$ & Kedisiplinan & $\begin{array}{c}\text { Integritas } \\
\text { (Kesungguhan) }\end{array}$ \\
\hline 1 & A1 & 75 & 75 & 50 & 75 & 50 \\
\hline 2 & A2 & 75 & 75 & 75 & 100 & 75 \\
\hline 3 & A3 & 75 & 75 & 50 & 75 & 75 \\
\hline 4 & A4 & 50 & 50 & 100 & 75 & 50 \\
\hline 5 & A5 & 50 & 50 & 50 & 50 & 75 \\
\hline 6 & A6 & 75 & 50 & 100 & 75 & 50 \\
\hline 7 & A7 & 75 & 50 & 75 & 75 & 50 \\
\hline 8 & A8 & 100 & 100 & 100 & 50 & 75 \\
\hline 9 & A9 & 75 & 100 & 100 & 100 & 100 \\
\hline 10 & A10 & 100 & 100 & 75 & 75 & 100 \\
\hline
\end{tabular}

\subsection{Proses Algoritma TOPSIS}

Langkah - langkah perhitungan TOPSIS sebagai berikut :

Menetukan normalisasi matriks keputusan dengan rumus (1).

Perhitungan :

$$
\begin{aligned}
&|\mathrm{X} 1|= \mathrm{R}_{11}=\frac{75}{\sqrt{75^{2+} 75^{2+} 75^{2+} 50^{2+} 50^{2}+75^{2+} 75^{2+} 100^{2+} 75^{2+} 100^{2}}}=0,309426 \\
& \mathrm{R}_{21}=\frac{75}{\sqrt{75^{2+} 75^{2+} 75^{2+} 50^{2+} 50^{2}+75^{2+} 75^{2+} 100^{2+} 75^{2+} 100^{2}}}=0,309426 \\
& \mathrm{R}_{31}=\frac{75}{\sqrt{75^{2+} 75^{2+} 75^{2+} 50^{2+} 50^{2}+75^{2+} 75^{2+} 100^{2+} 75^{2+} 100^{2}}}=0,309426 \\
& \mathrm{R}_{41}=\frac{50}{\sqrt{75^{2+} 75^{2+} 75^{2+} 50^{2+}+0^{2}+75^{2+} 75^{2+} 100^{2+} 75^{2+} 100^{2}}}=0,206284 \\
& \mathrm{R}_{51}=\frac{50}{\sqrt{75^{2+} 75^{2+} 75^{2+} 50^{2+} 50^{2}+75^{2+} 75^{2+} 100^{2+} 75^{2+} 100^{2}}}=0,206284 \\
& \mathrm{R}_{61}=\frac{75}{\sqrt{75^{2+} 75^{2+} 75^{2+} 50^{2+} 50^{2}+75^{2+} 75^{2+} 100^{2+} 75^{2+} 100^{2}}}=0,309426
\end{aligned}
$$




$$
\begin{aligned}
& \mathrm{R}_{71}=\frac{75}{\sqrt{75^{2+} 75^{2+} 75^{2+} 50^{2+} 50^{2}+75^{2+} 75^{2+} 100^{2+} 75^{2+} 100^{2}}}=0,309426 \\
& \mathrm{R}_{81}=\frac{100}{\sqrt{75^{2+} 75^{2+} 75^{2+} 50^{2+} 50^{2}+75^{2+} 75^{2+} 100^{2+} 75^{2+} 100^{2}}}=0,412568 \\
& \mathrm{R}_{91}=\frac{75}{\sqrt{75^{2+} 75^{2+} 75^{2+} 50^{2+} 50^{2}+75^{2+} 75^{2+} 100^{2+} 75^{2+} 100^{2}}}=0,309426 \\
& \mathrm{R}_{101}=\frac{100}{\sqrt{75^{2+} 75^{2+} 75^{2+} 50^{2+} 50^{2}+75^{2+} 75^{2+} 100^{2+} 75^{2+} 100^{2}}}=0,412568
\end{aligned}
$$

Dan seterusnya sampai |X10| Maka,
$\mathrm{R}=\left[\begin{array}{l}0,309426 \\ 0,309426 \\ 0,309426 \\ 0,206284 \\ 0,206284 \\ 0,309426 \\ 0,309426 \\ 0,412568 \\ 0,309426 \\ 0,412568\end{array}\right.$
0,314485
0,197066
0,309426
0,218218
0,314485
0,295599
0,412568
0,327327
0,314485
0,197066
0,309426
0,327327
0,209657
0,394132
0,309426
0,218218
$0,2096570,197066$
0,206284
0,327327
$0,209657 \quad 0,394132$
0,309426
0,218218
$0,2096570,295599$
0,309426
0,218218
$0,419314 \quad 0,394132$
0,206284
0,327327
$0,419314 \quad 0,394132$
0,412568
0,436436
0,419314
0,295599
0,309426
0,436436

Nilai bobot ternormalisasi didapat berdasarkan rumus (2).

Perhitungan :

$\mathrm{Y}_{11}=3 * 0,309426=0,928279$

$\mathrm{Y}_{21}=3 * 0,309426=0,928279$

$\mathrm{Y}_{31}=3 * 0,309426=0,928279$

$\mathrm{Y}_{41}=3 * 0,206284=0,618853$

$\mathrm{Y}_{51}=3 * 0,206284=0,618853$

$\mathrm{Y}_{61}=3 * 0,309426=0,928279$

$\mathrm{Y}_{71}=3 * 0,309426=0,928279$

$\mathrm{Y}_{81}=3 * 0,412568=1,237705$

$\mathrm{Y}_{91}=3 * 0,309426=0,928279$

$\mathrm{Y}_{101}=3 * 0,412568=1,237705$

Dan Seterusnya sampai $Y_{105}$. Maka,
$Y=\left[\begin{array}{l}0,928279 \\ 0,928279 \\ 0,928279 \\ 0,618853 \\ 0,618853 \\ 0,928279 \\ 0,928279 \\ 1,237705 \\ 0,928279 \\ 1,237705\end{array}\right.$
0,314485
0,295599
0,618853
0,545545
0,314485
0,443398
0,825137
0,818317
0,314485
0,295599
0,618853
0,818317
0,209657
0,591198
0,618853
0,545545
$0,209657 \quad 0,295599$
0,412568
0,818317
$0,209657 \quad 0,591198$
0,618853
0,545545
$0,209657 \quad 0,443398$
0,618853
0,545545
$0,419314 \quad 0,591198$
0,412568
0,818317
0,419314
0,591198
0,825137
1,091089
0,419314
0,443398
0,618853
1,091089

Menghitung solusi ideal positif atau negatif berdasarkan rumus (3).

Solusi Positif 
$y_{1}^{+}=\max$

$\{0,928279 ; 0,928279 ; 0,928279 ; 0,618853$;

$0,618853 ; 0,928279 ; 0,928279 ; 1,237705 ; 0,928279 ; 1,237705\}=1,237705$

$y_{2}^{+}=\max$

$\{0,314485 ; 0,314485 ; 0,314485 ; 0,209657$;

$0,209657 ; 0,209657 ; 0,209657 ; 0,419314 ; 0,419314 ; 0,419314\}=0,419314$

$y_{3}^{+}=\max$

$\{0,295599 ; 0,443398 ; 0,295599 ; 0,591198$;

$0,295599 ; 0,591198 ; 0,443398 ; 0,591198 ; 0,591198 ; 0,443398\}=0,591198$

$y_{4}^{+}=\max$

$\{0,618853 ; 0,825137 ; 0,618853 ; 0,618853$;

$0,412568 ; 0,618853 ; 0,618853 ; 0,412568 ; 0,825137 ; 0,618853\}=0,825137$

$y_{5}^{+}=\max$

$\{0,545545 ; 0,818317 ; 0,818317 ; 0,545545$;

$0,818317 ; 0,545545 ; 0,545545 ; 0,818317 ; 1,091089 ; 1,091089\}=1,091089$

$A^{+}=\{1,237705 ; 0,419314 ; 0,591198 ; 0,825137 ; 1,091089\}$

Solusi Negatif

$y_{1}^{-}=\min$

$\{0,928279 ; 0,928279 ; 0,928279 ; 0,618853$;

$0,618853 ; 0,928279 ; 0,928279 ; 1,237705 ; 0,928279 ; 1,237705\}=0,618853$

$y_{2}^{-}=\min$

$\{0,314485 ; 0,314485 ; 0,314485 ; 0,209657$;

$0,209657 ; 0,209657 ; 0,209657 ; 0,419314 ; 0,419314 ; 0,419314\}=0,209657$

$y_{3}^{-}=\min$

$\{0,295599 ; 0,443398 ; 0,295599 ; 0,591198$;

$0,295599 ; 0,591198 ; 0,443398 ; 0,591198 ; 0,591198 ; 0,443398\}=0,295599$

$y_{4}^{-}=\min$

$\{0,618853 ; 0,825137 ; 0,618853 ; 0,618853$;

$0,412568 ; 0,618853 ; 0,618853 ; 0,412568 ; 0,825137 ; 0,618853\}=0,412568$

$y_{5}^{-}=\min$

$\{0,545545 ; 0,818317 ; 0,818317 ; 0,545545$;

$0,818317 ; 0,545545 ; 0,545545 ; 0,818317 ; 1,091089 ; 1,091089\}=0,545545$ $A^{-}=\{0,618853 ; 0,209657 ; 0,295599 ; 0,412568 ; 0,545545\}$

Jarak antara masing-masing alternatif dengan solusi ideal positif berdasarkan rumus (4).

Untuk solusi ideal positif

$$
D_{1}^{+}=0,730948
$$


$D_{2}^{+}=0,450536$

$D_{3}^{+}=0,557737$

$D_{4}^{+}=0,875846$

$D_{5}^{+}=0,871166$

$D_{6}^{+}=0,692729$

$D_{7}^{+}=0,708320$

$D_{8}^{+}=0,494588$

$D_{9}^{+}=0,309426$

$D_{10}^{+}=0,253767$

Untuk solusi ideal negatif
$D_{1}^{-}=0,386377$

$D_{2}^{-}=0,610898$

$D_{3}^{-}=0,472961$

$D_{4}^{-}=0,360461$

$D_{5}^{-}=0,272772$

$D_{6}^{-}=0,475054$

$D_{7}^{-}=0,400178$

$D_{8}^{-}=0,767280$

$D_{9}^{-}=0,833613$

$D_{10}^{-}=0,888230$

Dilanjutkan dengan pencarian nilai prefensi untuk setiap alternatif (Vi) dengan rumus (5).

Perhitungan:

$$
\begin{aligned}
& \mathrm{V} 1=\frac{0,386377}{(0,386377+0,730948)}=0,345805 \\
& \mathrm{~V} 2=\frac{0,610898}{(0,610898+0,450536)}=0,57554 \\
& \mathrm{~V} 3=\frac{0,472961}{(0,472961+0,557737)}=0,458874 \\
& \mathrm{~V} 4=\frac{0,360461}{(0,360461+0,875846)}=0,291562 \\
& \mathrm{~V} 5=\frac{0,272772}{(0,272772+0,871166)}=0,23845 \\
& \mathrm{~V} 6=\frac{0,475054}{(0,475054+0,692729)}=0,4068 \\
& \mathrm{~V} 7=\frac{0,400178}{(0,400178+0,708320)}=0,361009 \\
& \mathrm{~V} 8=\frac{0,767280}{(0,767280+0,494588)}=0,729295 \\
& \mathrm{~V} 9=\frac{0,833613}{(0,833613+0,309426)}=0,729295 \\
& \mathrm{~V} 10=\frac{0,888230}{(0,888230+0,253767)}=0,777786
\end{aligned}
$$

\subsection{Hasil}

Dapat disimpulkan bahwa berdasarkan metode TOPSIS maka diperoleh 8 alternatif dengan peringkat yang paling tinggi adalah A10, A9, A8, A2, A3, A6, A7, A1 atau Eka Satria Pribadi, Erlangga Amara Putra Samodra, Awaluddin Kurniawan, Hanifa Urbach Sari, Ella Tri Nadia, Huda Fadiya Daulay, Azhar Fadilah Zuhri , Retno Rafika sebagai mahasiswa/i yang terpilih menjadi leader official pada PKKMB AMIK dan STIKOM Tunas Bangsa Pematangsiantar.

\section{KESIMPULAN}

Pada Penerapan Metode Topsis Dalam Pemilihan Leader Official PKKMB Terbaik dapat disimpulkan sebagai berikut :

a. Prosedur penentuan mahasiswa/i menjadi Leader Official, dimulai dari mahasiswa/i melamar menjadi calon Leader Official. Kemudian dilakukan wawancara dengan penentuan penilaian dari beberapa aspek seperti IPK, Semester , Pegalaman organisasi, kedisiplinan dan integritas(kesungguhan). 
b. Metode Techinique for Order Preference by Similarity to Ideal Solution (TOPSIS) sangat cocok diterapkan dalam sistem pendukung keputusan, untuk menghitung serta memberikan hasil akhir penilaian yang telah dirankingkan sehingga dapat menentukan mahasiswa/i yang akan terpilih menjadi menjadi Leader Official dengan tepat.

c. Dari penelitian ini penulis dapat membantu pihak kemahasiswaan untuk memutuskan apakah mahasiswa/i tersebut sudah memenuhi kriteria untuk menjadi Leader Official terbaik pada PKKMB.

Untuk mendapatkan hasil yang maksimal, kedepannya penelitian ini diharapkan lebih memperbanyak kriteria penilaian dan membuat aplikasinya, baik itu berbasis web, dekstop atau android. Dengan ketentuan untuk memilih leader official di lakukan wawancara terlebih dahulu kepada calon mahasiswa yang ingin menjadi leader official lalu kemudian data yang di peroleh dari hasil wawancara di olah kedalam perhitungan, kemudian dilanjut dengan pembuatan aplikasi.

\section{DAFTAR PUSTAKA}

[1] K. Riset, D. A. N. P. Tinggi, D. Jenderal, P. Dan, D. Jenderal, and P. Dan, "Kementerian riset, teknologi, dan pendidikan tinggi," vol. 57946100, 2016.

[2] S. Mallu and S. P. Keputusan, "Sistem pendukung keputusan penentuan karyawan kontrak menjadi karyawan tetap menggunakan metode topsis," vol. I, no. 2, pp. 36-42, 2015.

[3] S. M. M. Ahp-topsis, D. R. Sari, A. P. Windarto, and D. Hartama, "Sistem Pendukung Keputusan untuk Rekomendasi Kelulusan Sidang,” vol. 6, no. November 2017, pp. 1-6, 2018.

[4] N. G. Perdana and T. Widodo, "Sistem Pendukung Keputusan Pemberian Beasiswa Kepada Peserta Didik Baru Menggunakan Metode TOPSIS," vol. 2013, no. November, pp. 265-272, 2013.

[5] W. Fadillah, "No Title," vol. 10, no. 1, 2018.

[6] R. A. Hutasoit, S. Solikhun, and A. Wanto, "Analisa Pemilihan Barista dengan Menggunakan Metode TOPSIS (Studi Kasus: Mo Coffee)," KOMIK (Konferensi Nasional Teknologi Informasi dan Komputer), vol. 2, no. 1, pp. 256-262, 2018.

[7] T. Imandasari, A. Wanto, and A. P. Windarto, "Analisis Pengambilan Keputusan Dalam Menentukan Mahasiswa PKL Menggunakan Metode PROMETHEE," Jurnal Riset Komputer (JURIKOM), vol. 5, no. 3, pp. 234-239, 2018.

[8] M. Masitha, D. Hartama, and A. Wanto, "Analisa Metode (AHP) pada Pembelian Sepatu Sekolah Berdasarkan Konsumen," Seminar Nasional Sains \& Teknologi Informasi (SENSASI), vol. 1, no. 1, pp. 338-342, 2018.

[9] S. R. Ningsih, D. Hartama, A. Wanto, I. Parlina, and Solikhun, "Penerapan Sistem Pendukung Keputusan Pada Pemilihan Objek Wisata di Simalungun," in Seminar Nasional Teknologi Komputer \& Sains (SAINTEKS), 2019, pp. 731-735.

[10] L. P. Purba, A. P. Windarto, and A. Wanto, "Faktor Terbesar Rendahnya Minat Ber-KB (Keluarga Berencana) dengan Metode ELECTRE II," Seminar Nasional Sains \& Teknologi Informasi (SENSASI), vol. 1, no. 1, pp. 369-374, 2018.

[11] N. Rofiqo, A. P. Windarto, and A. Wanto, "Penerapan Metode VIKOR Pada Faktor Penyebab Rendahnya Minat Mahasiswa Dalam Menulis Artikel Ilmiah," Seminar Nasional Sains \& Teknologi Informasi (SENSASI), vol. 1, no. 1, pp. 228-237, 2018.

[12] S. Sundari, S. M. Sinaga, I. S. Damanik, and A. Wanto, "Sistem Pendukung Keputusan Pemilihan Peserta Olimpiade Matematika SMA Swasta Teladan Pematangsiantar Dengan Metode Electre," in Seminar Nasional Teknologi Komputer \& Sains (SAINTEKS), 2019, pp. 793-799.

[13] S. Sundari, A. Wanto, Saifullah, and I. Gunawan, "Sistem Pendukung Keputusan Dengan Menggunakan Metode Electre Dalam Merekomendasikan Dosen Berprestasi Bidang Ilmu Komputer (Study Kasus di AMIK \& STIKOM Tunas Bangsa)," in Seminar Nasional Multi Disiplin Ilmu, 2017, pp. 1-6. 
[14] A. Wanto and H. Damanik, "Analisis Penerapan Sistem Pendukung Keputusan Terhadap Seleksi Penerima Beasiswa BBM (Bantuan Belajar Mahasiswa) Pada Perguruan Tinggi Menggunakan Metode Simple Additive Weighting (SAW) (Studi Kasus : AMIK Tunas Bangsa Pematangsiantar)," in Seminar Nasional Rekayasa (SNTR) II, 2015, no. 2, pp. 323-333.

[15] A. Wanto and E. Kurniawan, "Seleksi Penerimaan Asisten Laboratorium Menggunakan Algoritma AHP Pada AMIK-STIKOM Tunas Bangsa Pematangsiantar," Jurnal Informatika dan Komputer (JIKO), vol. 3, no. 1, pp. 11-18, 2018.

[16] M. Widyasuti, A. Wanto, D. Hartama, and E. Purwanto, "Rekomendasi Penjualan Aksesoris Handphone Menggunakan Metode Analitycal Hierarchy Process (AHP)," Konferensi Nasional Teknologi Informasi dan Komputer, vol. 1, no. 1, pp. 27-32, 2017.

[17] H. Faqih and J. Irigasi, "Implementasi dss dengan metode saw untuk menentukan prioritas pekerjaan operasi dan pemeliharaan sistem irigasi dpu kabupaten tegal," no. 1, pp. 19-32, 2014.

[18] I. Metode, T. Dan, and S. A. W. Dalam, "Implementasi metode topsis dan saw dalam memberikan reward pelanggan," vol. 4, no. 1, pp. 88-101, 2017. 